\title{
Oficina de Orientação Profissional em uma Escola Pública: Uma Abordagem Psicossocial
}

Vocational Guidance Workshop in a Public High School: A Psychosocial Approach

Oficina de Orientación Profesional en una Escuela Pública: Un Abordaje Psicosocial

Luiz Gustavo Silva Souza, Maria Cristina Smith Menandro, Milena Bertollo \& Rafaela Kerckhoff Rolke

Universidade Federal do Espírito Santo

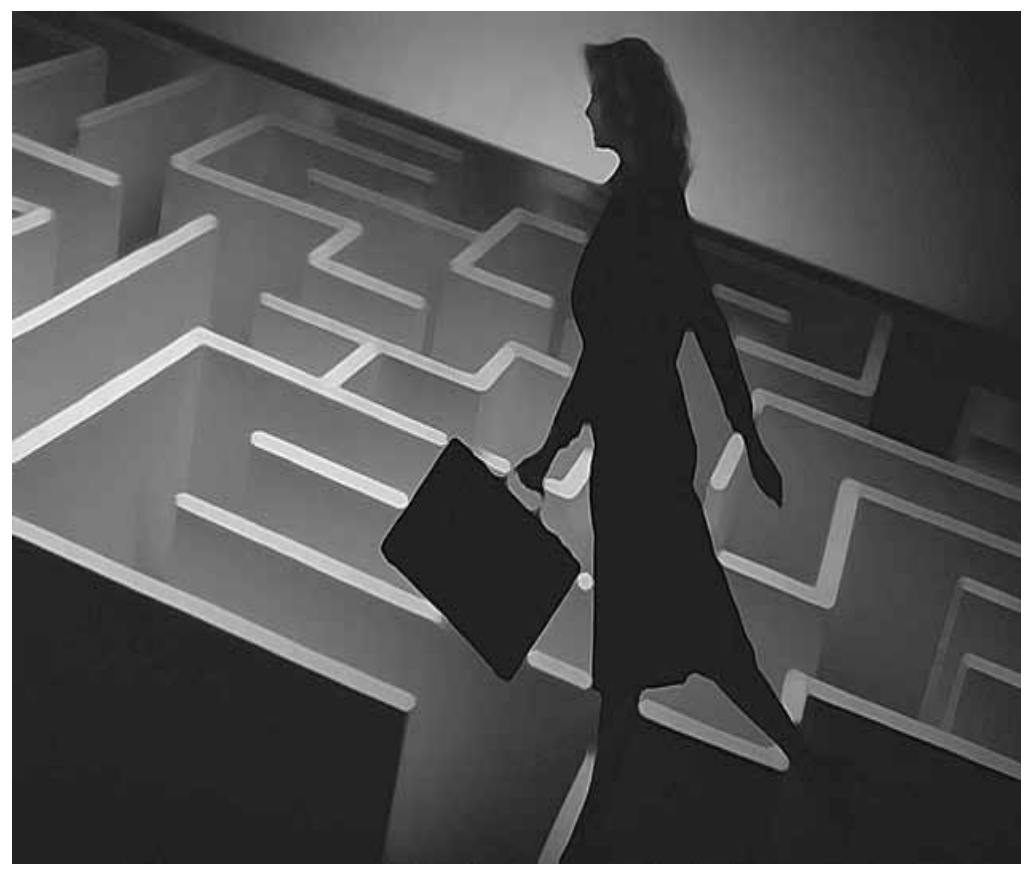


Resumo: O objetivo deste artigo é relatar uma intervenção com orientação profissional realizada em uma escola pública de ensino médio, com estudantes do 3ํano (17 a 20 anos de idade). A oficina foi conduzida em oito encontros semanais, com duração de duas horas cada, e partiu de um enfoque psicossocial, com base em uma avaliação crítica da sociedade e do trabalho e com o objetivo de ampliar a consciência dos indivíduos sobre o contexto escolar, familiar e laboral que os cerca, favorecendo a atitude de participação ativa frente aos diversos determinantes da escolha profissional. Neste artigo, descrevemos os procedimentos utilizados, incluindo técnicas de grupo e questionários abertos, com enfoque qualitativo, criados especificamente para a intervenção. Debatemos, com os participantes, o cotidiano escolar e as idéias naturalizadas sobre o sucesso pessoal. Apresentamos e discutimos informações objetivas sobre cursos e profissões, e envolvemos os estudantes em uma atividade de pesquisa sobre profissões, realizada por meio de entrevistas. Ao final da intervenção, os estudantes relataram maior segurança frente aos planos de futuro e à escolha profissional e avaliaram positivamente a oficina proposta.

Palavras-chave: Orientação profissional. Escola pública. Ensino médio. Intervenção psicossocial.

\begin{abstract}
The aim of this paper is to describe a vocational guidance workshop that took place in a Brazilian public high school, with students of the 3 rd year (17 to 20 years old). The workshop had eight sessions, two hours each. It was based on a psychosocial approach, including a critical point of view about society and work. Its main objective was to expand the individuals' consciousness about the surrounding context (school, family, work) and to foster an attitude of active participation towards the determinants of professional choice. In this paper, we describe the workshop procedures, including group techniques and open qualitative questionnaires, designed specifically for the workshop. Together with the students, we discussed the following subjects: school experiences, ideals of personal success and the characteristics of some professions. We also asked the students to do research about the professions using interviews. After the workshop, the students reported that they were more confident about their future plans and more prepared to make a professional choice.
\end{abstract}

Keywords: Vocational guidance. Public education. High school. Psychosocial intervention.

Resumen: El objetivo de este artículo es relatar una intervención con orientación profesional realizada en una escuela pública de enseñanza media, con estudiantes del 3ํo año (17 a 20 años de edad). El taller fue conducido en ocho encuentros semanales, con duración de dos horas cada, y partió de un enfoque psicosocial, con base en una evaluación crítica de la sociedad y del trabajo y con el objetivo de ampliar la conciencia de los individuos sobre el contexto escolar, familiar y laboral que los rodea, favoreciendo la actitud de participación activa frente a los diversos determinantes de la elección profesional. En este artículo, describimos los procedimientos utilizados, incluyendo técnicas de grupo y cuestionarios abiertos, con enfoque cualitativo, creados específicamente para la intervención. Debatimos, con los participantes, el cotidiano escolar y las ideas naturalizadas sobre el éxito personal. Presentamos y discutimos informaciones objetivas sobre cursos y profesiones, e involucramos a los estudiantes en una actividad de pesquisa sobre profesiones, realizada por medio de entrevistas. Al final de la intervención, los estudiantes relataron mayor seguridad frente a los planes de porvenir y a la elección profesional y evaluaron positivamente el taller propuesto. Palabras clave: Orientación profesional. Escuela pública. Enseñanza media. Intervención psicosocial.

O presente relato descreve uma intervenção com Orientação Profissional (OP) realizada em uma escola pública de ensino médio localizada em Viana, ES. Pretende-se contribuir com o debate sobre algumas possibilidades da orientação profissional realizada em grupos e no âmbito da educação pública.

Nas últimas décadas, caminhamos para a progressiva valorização das estratégias de OP com grupos voltadas para as camadas empobrecidas da população. Abade (2005) realizou uma revisão histórica da produção científica em OP, buscando as relações entre essa produção e o contexto sociopolítico mais amplo. A autora mostrou que um número crescente de autores enfatizou a necessidade de direcionar as práticas de OP para os setores empobrecidos da sociedade, em vez de concentrá-las nos jovens das elites. Esses autores passaram a questionar as perspectivas tecnicistas, baseadas na lógica da vocação, e buscaram propostas que 
contemplassem as determinações sociais e que não individualizassem as causas do fracasso escolar e laboral.

Abade (2005) afirma que as perspectivas atuais em OP se caracterizam pela pluralidade teórica e metodológica, com três vertentes principais que podem ser claramente identificadas a partir da década de 1990: a psicométrica, a clínica e a psicossocial, com predominância dos dois primeiros enfoques.

A intervenção aqui relatada partiu do enfoque psicossocial, que valoriza a importância da interface entre OP e Psicologia social e que é representado por autores como Sarriera (2000), Bock (1995, 2002) e Bock e Aguiar (1995).

Sarriera (2000) fornece referências para caracterizar uma intervenção psicossocial. Discute as noções de facilitador-interventor e de grupo-alvo, aborda os objetivos de uma intervenção psicossocial e sugere etapas para sua elaboração. Bock faz uma crítica à concepção liberal de orientação profissional, pautada na valorização de um mero ajuste dos indivíduos a uma realidade social já dada e imutável. O autor defende a idéia de que a OP deve buscar envolver os participantes na compreensão e na transformação de sua realidade histórico-social.

Com base nesses trabalhos, definimos orientação profissional como uma intervenção psicossocial que tematiza especialmente a relação entre homem, educação e trabalho. Nesse tipo de intervenção, objetiva-se ampliar a consciência dos indivíduos sobre os determinantes do contexto que os cerca, fornecendo instrumentos para a ação e para a transformação desse contexto. O objetivo geral da OP é favorecer uma "boa" escolha profissional, definida como aquela que é feita a partir de uma análise crítica da sociedade e do trabalho, e que é tomada por um sujeito que se sente participante ativo da construção de sua própria história e do mundo em que vive.
Bastos (2005) afirma que a OP não deve ser encarada como um luxo destinado às classes mais abastadas. Sua inserção nas escolas públicas poderia fornecer oportunidades de os estudantes discutirem a sociedade e os significados da escolha profissional, o que os prepararia para uma entrada mais crítica e consciente no mundo do trabalho. A OP pode contribuir para questionar informações estereotipadas sobre as profissões, para fornecer dados mais reais sobre os diversos contextos de trabalho e para refletir sobre os determinantes concretos das escolhas.

Partindo dessas referências teóricas, constituímos uma equipe de intervenção e elaboramos uma proposta de oficina de OP. A equipe foi formada por um psicólogo, que atuou como moderador, duas estudantes de Psicologia, que foram co-moderadoras, e uma professora de Psicologia, que supervisionou o trabalho.

\section{Descrição da experiência}

A oficina foi realizada em uma escola pública de ensino médio de Viana, entre os meses de agosto a outubro de 2005. A escola se situa em um bairro de periferia urbana, na região metropolitana de Vitória (capital do ES), e atende cerca de mil alunos. Após contato com a direção da escola para definir, em conjunto, os detalhes de nossa proposta, ficou acertado que a oficina seria oferecida a alunos do $3^{\circ}$ ano do período noturno que estivessem interessados nessa atividade. Realizamos oito encontros, em semanas consecutivas, no turno vespertino, e cada encontro durou cerca de duas horas.

Em nossos primeiros encontros, contamos com a participação de onze alunos, aos quais faremos referência ao longo do relato e que caracterizaremos a seguir com nomes fictícios: Carolina, Marcelo, Júlio, Clara, Beatriz, Iara, Laura, Andréia, Joana, Caetano e Luciano. Todos tinham entre 17 e 20 anos, exceto Júlio, que tinha 33 anos e que, após um acidente que o deixou paraplégico, tinha voltado recentemente aos bancos escolares. 
"As finalidades e propósitos dos grupos operativos podem ser resumidos

dizendo-se que sua atividade está centrada na mobilização de estruturas, estereotipadas por causa do montante de ansiedade despertada por toda mudança"

(Pichon-Rivière, 1983, p. 98).
No primeiro encontro com os estudantes, percebemos que a proposta da oficina não estava clara para eles. Alguns não tinham qualquer informação sobre o que aconteceria ali e fizeram-se presentes pela curiosidade. Outros se sentiram atraídos pelo fato de ser "um trabalho com o pessoal da Psicologia". O procedimento inicial, então, foi expor nossa proposta e esclarecer que não pretendíamos utilizar testes psicológicos e que os estudantes não deveriam esperar um diagnóstico, dado por outrem, que lhes mostrasse a decisão profissional correta. Explicamos que trabalharíamos com técnicas de grupo, para gerar debates sobre tópicos relevantes, e que esperávamos que todos participassem ativamente desses debates e de outras atividades da oficina.

Realizamos, em princípio, uma técnica de grupo que incluía a apresentação dos participantes. Além de certos elementos tradicionais de uma apresentação (nome, se trabalha ou não, onde trabalha), pedimos que todos relatassem algo que gostassem muito de fazer e realizassem com freqüência em seu cotidiano. Desde os primeiros momentos, procuramos manter um clima de descontração. Também foi solicitado aos participantes que escrevessem uma carta a um amigo fictício, falando sobre a escola e sobre o que esperavam do futuro profissional. Verificamos que algumas dessas cartas traziam declarações que traduziam ansiedade e insegurança com relação ao futuro profissional. Discutimos esses elementos de forma preliminar e informamos que os dois encontros seguintes estariam focados na vida escolar, e que, a partir do quarto encontro, abordaríamos mais explicitamente a questão da escolha profissional.

No segundo e no terceiro encontros, portanto, realizamos principalmente debates sobre o cotidiano escolar. Uma das reflexões que propusemos foi baseada na seguinte questão: Quais são os principais fatores que levam os estudantes a gostar da escola, a gostar de estudar? Os participantes responderam que dependem de um bom professor para gostar de estudar, e que esse é o fator preponderante. Se o professor é ruim, o desempenho também o será. As falas iniciais deixaram entrever uma idéia comum entre os estudantes: a de que eles não poderiam ter uma influência ativa sobre os processos escolares. Essa condição de dependência foi analisada e questionada nesses dois encontros: focalizamos as iniciativas que os estudantes já tomavam e que os colocavam na condição de protagonistas de sua história escolar (conversas com os professores sobre a condução das aulas, reivindicações para a direção, etc.).

É preciso destacar que, nesses três primeiros encontros, os próprios estudantes revelaram uma grande vontade de falar da escola. Esse dado é interessante, já que a literatura sobre Sociologia e Psicologia da educação nos mostra que a escola se constituiu historicamente em um espaço hegemônico destinado a silenciar os estudantes, um espaço de hierarquização e de adestramento (Enguita, 1989; Patto, 2000; Zanella, 2003).

Consideramos relevantes os debates sobre o cotidiano escolar no início de nossa oficina, por terem quebrado um pouco esse silêncio. Isso mostra a possibilidade de aproveitar a intervenção com OP para abrir um espaço de expressão para os jovens no contexto da educação pública. Além disso, pensamos que o questionamento da posição de dependência e passividade dos alunos frente aos processos escolares tenha proporcionado vantagens para a seqüência de nosso trabalho. A partir do momento em que se colocaram como pensadores ativos dos determinantes de seu contexto escolar (que é central para os jovens), os estudantes puderam se colocar também, com mais facilidade, como avaliadores ativos dos determinantes da escolha e do futuro profissional.

Iniciamos a abordagem mais sistematizada desses temas, escolha profissional e futuro, no quarto encontro. Estudos mostram que 
a escola é representada pelos jovens como caminho para um futuro melhor, para ser alguém na vida (por exemplo: Matos, 2003; Oliveira, Sá, Fischer, Martins, \& Teixeira, 2001). No quarto encontro, buscamos esmiuçar essas idéias com as seguintes questões: "O que significa ter sucesso no futuro pessoal e profissional?"; "O que é ser alguém na vida?" Propusemos como atividade principal o debate de "afirmações polêmicas", que foram as seguintes: "Temos que estudar para sermos alguém na vida", e "Qualquer pessoa é livre para escolher a profissão que deseja".

Todos os estudantes afirmaram que a possibilidade de ser livre para escolher a profissão que deseja não está disponível para qualquer pessoa. Segundo a opinião do grupo, o maior impedimento para essa liberdade é a condição financeira: somente pessoas que já têm bastante dinheiro podem se dar ao luxo de escolher a profissão livremente. Os que não se encontram nessa condição devem considerar principalmente a questão financeira: escolher uma atividade que proporcione retorno financeiro rápido, em boa quantidade e de forma estável. Além disso, outros determinantes foram citados, como as pressões familiares. Sobretudo os pais apareceram como agentes que pressionam pelo rápido ingresso no mercado e pela escolha profissional que traga garantia de retorno financeiro. Para esses estudantes, deveriam ser consideradas, ainda, as condições de acesso aos cursos superiores, a quantidade de vagas disponíveis no mercado de trabalho e as atuais exigências das empresas.

Todos concordaram com a afirmação de que devemos estudar para ser "alguém na vida". A discussão dessa afirmação fez aparecer os sentidos negativos associados à escola pública. Os estudantes afirmaram, por exemplo, que a educação oferecida não é suficiente para passar em concursos ou vestibulares. Afirmaram que precisam estudar para ser alguém na vida porque só o estudo seria capaz de dar acesso às ocupações mais valorizadas socialmente e disseram também que as empresas exigem qualificação cada vez maior.

Em meio a esse debate sobre a necessidade do estudo, pudemos observar a expressão de crenças associadas ao sucesso pessoal e profissional. "Ser alguém na vida" apareceu inicialmente com as seguintes características: estudar em boas escolas, estar plenamente qualificado para as novas exigências do mercado de trabalho, vencer a competição por uma vaga em um mercado naturalmente excludente, ganhar muito dinheiro, ter casa própria e outros bens, atuar profissionalmente com algo de que se goste, que responda à vocação natural, destacar-se na multidão, ter status, ter independência em relação aos pais e ao resto da sociedade.

Esses sentidos atribuídos ao sucesso são muito condizentes com aqueles analisados por Bock e Liebesny (2003) em sua pesquisa sobre os projetos de vida de estudantes de escolas públicas e particulares de São Paulo. Esses projetos são essencialmente centrados no indivíduo, em sua realização pessoal e na repetição dos modelos hegemônicos de organização social. Aproximam-se, portanto, da visão de homem liberal, com a valorização do mérito individual e de sua exclusividade na explicação do sucesso e do fracasso. A crença de que a profissão escolhida deve responder a uma vocação natural dos indivíduos também foi detectada no estudo de Aguiar e Ozella (2003). Tal estudo mostrou que os estudantes basearam seu pensamento na suposição que o indivíduo possui dons e características intrínsecas e que ele é o único responsável por seu sucesso ou fracasso. Tendo em vista a enorme dificuldade de cumprir o modelo hegemônico de sucesso, é possível que os estudantes freqüentemente avaliem sua própria condição por processos de autodesqualificação.

Atentos ao discurso assumido hegemonicamente pelos estudantes, procuramos fomentar 
uma discussão sobre os pressupostos que o embasavam. Os moderadores buscaram formular questões que desafiassem os estudantes a rever esses sentidos naturalizados atribuídos ao indivíduo, ao sucesso e à escolha profissional: O que é ser alguém na vida? Quem não estuda é "ninguém na vida"? O sucesso está sempre ligado ao dinheiro e ao status?

A partir dessas questões e das falas dos próprios colegas, os estudantes realizaram uma interessante ampliação dos significados que atribuíam ao sucesso. À medida que refletiam sobre esse tema, passaram a afirmar que ser alguém na vida é também saber relacionar-se com as pessoas, saber aprender com elas, "ter bom caráter", "boa personalidade", assumir uma identidade profissional importante por sua funcionalidade social (não só para se destacar individualmente), entender $\mathrm{o}$ mundo, estar bem informado sobre o que se passa à sua volta, saber dos seus direitos e lutar por eles, esforçar-se no trabalho, ser envolvido com o trabalho, conquistar posições com honestidade e luta, entender os desafios constantemente impostos pelo mundo material e social e saber lidar com eles.

Tivemos a oportunidade de construir uma análise coletiva, com a participação ativa dos estudantes. Tal análise foi capaz de deslocar um pouco a ênfase dada ao modelo de sucesso hegemônico, baseado na competição e no individualismo; simultaneamente, abriu a possibilidade de avaliação crítica de uma série de determinantes importantes para as decisões relativas ao futuro profissional dos jovens envolvidos, como a participação da escola, as relações interpessoais no trabalho, os direitos e deveres relacionados à cidadania e o papel social do trabalho. Especialmente interessante foi o surgimento da idéia de que ser alguém na vida inclui compreender a realidade concreta à sua volta e agir no sentido de transformá-la.

Os participantes avaliaram o debate como bastante produtivo. Ao final desse encontro, propusemos uma atividade que deveria ser retomada no encontro seguinte, uma técnica do tipo "tempestade de idéias": os estudantes deveriam citar nomes de profissões rapidamente e ao acaso, conforme o que Ihes viesse à mente. Anotamos as profissões em um cartaz, na medida em que eles foram falando. Depois, perguntamos quais eram as profissões dos pais dos estudantes e também as anotamos no cartaz, dessa vez em um espaço separado.

Iniciamos o quinto encontro com a tarefa de avaliar o cartaz elaborado no encontro anterior. Aproveitamos para colocar em prática um procedimento que usamos desde o início da oficina e que chamamos de "devolução de análises". Tratava-se de um debate sobre os principais pontos trabalhados no encontro imediatamente anterior. Esse debate fortaleceu um sentido de continuidade da intervenção, e seu principal efeito foi o de favorecer as análises coletivas. Tanto os moderadores quanto os estudantes expunham o que haviam pensado, no intervalo entre um encontro e outro, sobre os temas discutidos.

Passamos ao cartaz e mostramos aos estudantes alguns dados interessantes que tínhamos notado em sua elaboração. Quando solicitados a nomear profissões ao acaso, os estudantes citaram as profissões de nível superior com prioridade e com maior freqüência. O cartaz foi composto de três colunas. Dentre as profissões citadas na primeira coluna, 20 associam-se diretamente a cursos de nível superior, enquanto apenas 7 vinculam-se a outros níveis de qualificação. A primeira profissão de nível técnico (secretária) só apareceu após terem mencionado nove profissões de nível superior. Chamamos a atenção também para o fato de que metade das profissões dos pais e mães dos estudantes não foi citada ao longo da elaboração do cartaz. Perguntamos o que achavam desse fato e por que profissões de nível superior apareciam mais.

Dentre os motivos apontados, os estudantes deram maior destaque à influência dos 
No ensino médio, parece não haver tempo ou espaço para discutir com os jovens o valor social das profissões e as relações entre escola e trabalho nem para promover o contato direto com diferentes profissões e o questionamento do vestibular como única via possível

(Sparta \& Gomes, 2005). jornais, das revistas e da televisão. Afirmaram que essas profissões são as que sempre aparecem com maior expressão e prestígio, como se fossem "mais profissões" do que as outras. Todos manifestaram a vontade de cursar o ensino superior.

Esse dado é condizente com o estudo de Sparta e Gomes, que pesquisaram a importância atribuída ao exame vestibular em alunos do ensino médio e verificaram que o vestibular foi a escolha dominante entre os jovens pesquisados, independentemente de gênero, tipo de escola (pública ou privada) e escolaridade dos pais. O curso superior foi enormemente valorizado por jovens de todas as classes. A opção por cursos técnicos profissionalizantes e a inserção direta no mercado de trabalho surgiu com maior freqüência entre os estudantes de escola pública. O ensino médio apareceu mais uma vez como mero curso preparatório para o ensino superior. No ensino médio, parece não haver tempo ou espaço para discutir com os jovens o valor social das profissões e as relações entre escola e trabalho nem para promover o contato direto com diferentes profissões e o questionamento do vestibular como única via possível (Sparta \& Gomes, 2005).

Os participantes de nossa oficina declararam que pretendiam tentar o vestibular da universidade pública ou apostar no atual programa de bolsas do Governo Federal destinado a financiar cursos em faculdades particulares. Alguns incluíam, em seus planos, um ano de preparação em cursinho prévestibular logo após o ensino médio.

Aproveitamos esse momento para chamar a atenção dos estudantes para as informações de que se dispõe na hora de escolher um curso superior. Os participantes confirmaram que nunca tinham conversado com representantes das profissões que lhes chamavam a atenção sobre seu cotidiano de trabalho. Afirmaram que, muitas vezes, pensavam em escolher esse ou aquele curso superior com base nas provas discursivas do vestibular, organizadas em torno das matérias que eles já conheciam, como geografia, português, Matemática, etc. Nesse momento, propusemos como atividade para a oficina uma "pesquisa sobre profissões" que deveria ser feita pelos estudantes, com a entrevista de um profissional da área escolhida. Todos concordaram com a proposta, que deveria ser retomada nos encontros posteriores.

Ainda no quinto encontro, entregamos aos estudantes um cartão com o seguinte título: "Três profissões que acho que poderia seguir ou que acho interessantes". Eles deveriam escrever o nome de três profissões e marcar uma delas, sem maiores compromissos, dentre essas três. Em seguida, formamos duplas entre os estudantes. Cada um deveria tentar convencer seu par a escolher aquela profissão que havia marcado em seu próprio cartão. Após cerca de vinte minutos, pedimos que cada participante explicasse ao grupo os argumentos que seu par utilizou para tentar convencê-lo.

Com essa técnica, tivemos acesso a interessantes informações sobre como os estudantes idealizavam as profissões escolhidas e sobre as vantagens que alegavam para embasar suas escolhas naquele momento. Como exemplos, lara afirmou que gostaria de ser diretora de marketing, pois assim passaria "o dia inteiro criando coisas interessantes para convencer os outros" e dando ordens para que outras pessoas executassem suas idéias; Clara disse que gostaria de ser estilista, pois assim poderia ganhar muito dinheiro e trabalhar em casa, perto de sua família; Beatriz afirmou que Psicologia seria uma boa opção de curso superior, pois poderia fazer com que "você se conheça melhor e conheça melhor os outros", preparando as pessoas para qualquer outro trabalho.

Após os relatos dos participantes, o moderador perguntou: "O que há de comum entre essas profissões?" "Se tivéssemos que fazer um quadro com a profissão ideal, como é que seria 
essa profissão?" As respostas dos estudantes deixaram claras algumas características: a profissão ideal seria intelectualizada, de nível superior, caracterizada pela criação ou pelo uso intenso da criatividade, uma atividade sempre empolgante e prazerosa, que traria uma boa recompensa financeira, que às vezes aparece como um objetivo de vida onipresente ("não terei tempo pra mais nada" - "será uma correria") e que às vezes aparece como o suporte necessário para algo mais importante, que é ter uma família.

Chamamos a atenção dos estudantes para os aspectos de sua argumentação que poderiam estar excessivamente idealizados ou baseados em fontes de informação demasiado escassas. Propusemos que, nos encontros subseqüentes, conversássemos mais sobre as profissões citadas e sobre outras profissões, trazendo, na medida dos nossos conhecimentos, informações mais concretas. Pedimos aos estudantes que avaliassem as características daquela "profissão ideal" sobre a qual conversamos e que pensassem se seria possível realizar esse ideal.

O sexto encontro foi decisivo no que diz respeito ao debate das idealizações feitas em torno das diferentes profissões. Inicialmente, passamos um bom tempo fazendo a "devolução de análises". Os estudantes contaram o que tinha acontecido nos encontros anteriores e falaram sobre o que tinham achado mais interessante. Lembraram-se das profissões enfatizadas na "tempestade de idéias" e de como elas se associam a status e a boa remuneração.

Uma das análises que fizemos com os estudantes se baseou no reconhecimento da falta de informação a respeito das possíveis profissões a serem escolhidas. Apontamos o fato de que, no encontro anterior, seus relatos permitiram saber que consideravam algumas profissões interessantes sem, contudo, indicar haverem tido qualquer contato com elas: não sabiam muito bem como chegar lá e o que faziam os profissionais daquelas áreas. As profissões e a escolha profissional em geral eram alvo, portanto, de diversas idealizações.

Pudemos verificar que, por um lado, as idealizações seexpressavam no desconhecimento de determinadas profissões. Por outro lado, atingiam o todo da escolha profissional. Isso acontecia na medida em que essa escolha era tida como uma opção "livre", de um sujeito "abstrato", que está isento dos determinantes sociais, familiares, financeiros, acadêmicos e como a opção "correta" de um sujeito "natural", que acredita possuir determinadas aptidões que devem ser postas em prática em uma atividade profissional específica. A escolha era idealizada também como momento irreversível, tomando contornos de um dispositivo "mágico" a partir do qual tudo na vida se transformaria. Sendo algo definitivo, a escolha deveria ser feita corretamente, sob pena de conseqüências graves. Essa idéia é ilustrada pela argumentação da Andréia: "É muito difícil escolher, porque pode ser pra sua vida toda, você vai ter que seguir aquilo. Já pensou se você escolher e der um passo errado? Você fica a vida toda marcada por aquilo que você não queria fazer".

Ao manter essa concepção de "homem livre que escolhe", um outro perigo se anuncia: frente às várias dificuldades próprias da inserção profissional, pode se construir, pouco a pouco, a certeza de que, aos jovens das classes populares, não cabe escolher uma profissão, e sim, resignar-se com os lugares socioprofissionais que estiverem sobrando.

Neste sexto encontro e nos encontros subseqüentes, colocamo-nos a tarefa de questionar os pressupostos das idéias apresentadas acima e que permeavam as representações dos estudantes sobre o futuro e a escolha profissional. Buscamos construir, com os participantes, uma análise a respeito da inexistência desse "sujeito ideal", abstrato, guiado unicamente por sua vocação e que faz uma "escolha ideal" e irreversível. 
Ainda nesse encontro, pedimos que os estudantes respondessem a um questionário que intitulamos "As cartas na mesa". Esse questionário tinha o seguinte enunciado: "Preencha o quadro abaixo pensando na profissão ou nas profissões que chamam a sua atenção neste momento da sua vida". As respostas deveriam ser dispostas em duas colunas, como no modelo abaixo:

Tabela 1. Formato do questionário "As cartas na mesa".

\begin{tabular}{|c|c|c|}
\hline Questão & Nome da profissão ou das profissões & Por quê? \\
\hline $\begin{array}{l}\text { Qual profissão ou quais } \\
\text { profissões eu quero? } \\
\text { Qual profissão ou quais } \\
\text { profissões minha família quer? } \\
\text { (outras questões) }\end{array}$ & & \\
\hline
\end{tabular}

As outras questões foram as seguintes: qual profissão ou quais profissões "eu posso desempenhar?", "são acessíveis para mim?", "conheço de perto?", "são mais fáceis?", "são mais difíceis?", "me custam mais financeiramente?" e "me custam mais emocionalmente?" Cada questão solicitava aos participantes que refletissem sobre um aspecto específico da escolha profissional. Depois do preenchimento do questionário, discutimos algumas respostas.

Outro recurso que utilizamos foram as "pesquisas sobre profissões". Cada estudante ficou responsável por entrevistar um trabalhador de alguma área que lhe chamasse a atenção, perguntando sobre seu percurso acadêmico e profissional, sobre seu cotidiano no trabalho, suas vantagens e dificuldades. Combinamos com os participantes que eles trariam os resultados dessas pesquisas para o debate do sétimo encontro.

Na semana seguinte, retomamos essa proposta. Entretanto, somente Andréia havia cumprido o combinado, tendo entrevistado uma pedagoga que trabalhava em outra escola. Mesmo assim, seu relato possibilitou o envolvimento de todos na discussão. Concentramo-nos no caso que ela apresentou durante todo o encontro, buscando enfatizar, durante o relato, pontos que poderiam ser analisados para a construção da escolha profissional.

Andréia iniciou seu relato contando um pouco sobre o percurso acadêmico da profissional entrevistada. A pedagoga disse que, no início, encontrou muitas dificuldades na faculdade e que não gostava do curso. Aos poucos, foi se encantando pela profissão e a experiência a fez ter a certeza de que era aquilo mesmo que ela queria. Aproveitamos a oportunidade para afirmar que é freqüente o fato de muitos estudantes se decepcionarem com o curso superior em seu início devido às muitas idealizações feitas ao escolhê-lo. Propusemos, em seguida, uma reflexão sobre as idealizações em relação a cursos ou profissões que eles pudessem estar fazendo naquele momento.

Andréia continuou seu relato, dizendo que a entrevistada atualmente gosta tanto de sua profissão que "está perdendo o crescimento dos dois filhos", porque trabalha muito. A partir dessa afirmação, questionamos o grupo mais uma vez, instigando-o a pensar e a debater sobre a possibilidade de se conjugar família e planos profissionais. 
Uma das estudantes opinou a respeito do trabalho feminino. Disse que é importante que a mulher seja financeiramente independente do homem e que ambos trabalhem e compartilhem as despesas. Outros pontos levantados a partir do relato da entrevista foram remuneração e número de vagas no mercado de trabalho. Os estudantes questionaram se esses aspectos devem ser considerados na hora de escolher a profissão.

Percebemos que, por meio do relato da entrevista e de sua discussão, os estudantes puderam avaliar criticamente alguns aspectos de um cotidiano profissional concreto. Isso Ihes possibilitou pensar não só em pontos positivos (tão freqüentes nas idealizações) mas também nas possíveis dificuldades encontradas em cada profissão e em outros aspectos de sua vida relacionados à escolha. Enfim, eles puderam refletir sobre seus próprios projetos de vida.

Aproveitamos para reforçar a proposta das pesquisas sobre profissões, e os participantes se comprometeram novamente a realizálas. Ao final do encontro, em clima de descontração, o grupo combinou um lanche para o encontro seguinte, um momento de confraternização para celebrar o encerramento da oficina.

Retomamos a proposta das pesquisas no oitavo e último encontro. Na ocasião, mais participantes haviam realizado a atividade. Entrevistaram um radialista, um professor de teatro, um mestre de obras, uma professora de moda e uma psicóloga. Ouvimos os relatos das entrevistas um a um e aproveitamos para realizar análises coletivas, assim como as que foram feitas no sétimo encontro. Novamente, os relatos trouxeram importantes reflexões sobre o mundo do trabalho, sobre os significados das escolhas profissionais, sobre os determinantes sociais, econômicos, familiares e pessoais dessas escolhas.

Nesse encontro, pedimos que os estudantes preenchessem um último instrumento, que chamamos de relatório final. Sua função foi promover um balanço geral da oficina e favorecer algumas conclusões a respeito dos principais tópicos abordados: o mundo do trabalho, a escolha profissional, a opção por um curso superior.

O relatório foi dividido em duas folhas. $\mathrm{Na}$ primeira, havia duas perguntas: "O que essa oficina significou para mim?" e "O que escolher? Como escolher?" A segunda folha continha um quadro intitulado "Que profissão ou profissões penso que podem ser boas para mim?" O quadro era composto de duas colunas, sendo a primeira intitulada "Profissão", e a segunda, "Porque pensei que essa profissão seja boa?" Havia cinco campos para colocar as profissões e, no final, uma questão "Outras?", seguida de algumas linhas.

Transcrevemos abaixo algumas respostas que os estudantes deram à primeira questão ("O que essa oficina significou para mim?"):

Esta oficina significou muito pra mim, pois com esta oficina me fez pensar sobre assuntos muito importantes. Eu, ao vir nesta oficina, dei o primeiro passo para crescer profissionalmente e conhecer a mim mesma!! (lara)

A minha grande satisfação de participar dessa oficina. Foi muito gratificante. Me inspirou e me mostrou que não é tão difícil como se parece. Teve muitos objetivos em si, como tentar nos mostrar um caminho e tentar também fazer com que sabemos que a satisfação de ter uma profissão não é só pelo dinheiro, e sim, pela responsabilidade e vontade de fazer o curso. Ensinar em si que, para formar grandes profissionais, temos que ter e começar com pequenos sonhos. (Andréia)

Acompanhemos agora como essas mesmas estudantes responderam às questões seguintes ("O que escolher?" "Como escolher?"):

No começo e no final, senti dúvidas, mas temos que tomar uma decisão e percebemos que não existem profissões erradas e que irão marcar de uma forma ruim a nossa 
vida... Então, ao escolher algo em nossa vida, temos que nos empenhar para assim obter o sucesso, para o nosso futuro e pra nós mesmos. (lara)

O que escolher é escolher o que eu me identifico mais, e como escolher: sempre pensar pequeno, mas bem mais na frente, e nunca atrás, sabendo sempre que devemos escolher o que nos faz bem. (Andréia)

Tendo como base o que os estudantes escreveram no relatório final, constatamos que estiveram envolvidos com a oficina e que os encontros se configuraram em espaços originais e relevantes em suas vidas naquele momento. Por meio da oficina, foi possível refletir sobre assuntos importantes que não encontravam caminhos de expressão. Nos depoimentos que transcrevemos acima, é possível verificar maior segurança e tranqüilidade com relação à escolha profissional, conceituada como nãodefinitiva. Parece ter havido uma relativização na idéia da escolha como momento mágico e irreversível.

Na segunda parte do relatório, os estudantes preencheram o quadro que descrevemos acima. Cada um citou duas profissões julgadas "boas para si". Foram feitas referências a profissões que demandam curso superior, como fisioterapia, marketing e pedagogia. Os participantes também falaram de profissões de formação técnica, como policial, vendedora e bombeiro. Houve duas citações a carreiras artísticas: música e dança. Para justificar as escolhas, utilizaram o argumento das preferências e dos talentos individuais, certos condicionantes do mercado de trabalho e a importância de tal ou qual profissão para a sociedade.

Pensamos que a contribuição mais importante que essa oficina proporcionou a seus participantes foi a construção de um espaço de maior protagonismo em relação aos projetos de futuro e à escolha profissional. Pudemos perceber, no início dos encontros, um discurso predominantemente marcado pela dependência e pela impotência diante da realidade escolar e social vivida pelos estudantes. Ao final da oficina, verificamos entre eles maior tranqüilidade e segurança diante dos projetos de futuro (sentimentos que puderam ser averiguados pessoalmente e que mostraram seus sinais nos relatórios finais). Além disso, os estudantes passaram de uma vontade (de certa forma "indefinida") de "ser alguém na vida" para o esboço de um real "projeto de futuro" (que inclui definir objetivos e estratégias). Os oito encontros que tivemos parecem ter contribuído para a produção de autonomia frente à escolha profissional, uma vez que os estudantes identificaram e analisaram ativamente vários de seus determinantes. Julgamos que a posição ativa dos participantes, ao longo das atividades programadas, foi o instrumento mais importante para a produção desses efeitos.

Ao final do oitavo encontro, os moderadores fizeram também uma avaliação da oficina e relataram aos estudantes as percepções descritas no parágrafo anterior. Todos os participantes concordaram com essa avaliação e fizeram mais algumas considerações sobre como tinham se transformado ao longo dos encontros. Depois disso, passamos à proposta feita pelos próprios estudantes: celebração com um lanche da tarde - mais um passo para transformar a escola em um ambiente um pouco mais "nosso".

\section{Considerações finais}

A oficina que realizamos enfatizou diferentes temas: a relação dos estudantes com seu contexto escolar, os significados sociais relacionados ao trabalho e ao sucesso pessoal e informações sobre as profissões e os diversos determinantes das escolhas profissionais. Esses temas, que estão entrecruzados, apareceram e reapareceram em diferentes momentos da intervenção.

Pensamos ser importante falar também sobre algumas limitações que encontramos. Houve diminuição do número de participantes: começamos com 11 e terminamos com 8 , e houve encontros em que nem todos 
esses 8 estudantes estiveram presentes. Ao mesmo tempo, sentimos que o número de encontros foi relativamente pequeno. Com um tempo maior, poderíamos ter consolidado algumas análises, explorando melhor o contexto familiar de cada participante, os determinantes singulares das preferências por tal ou qual atividade profissional e as habilidades envolvidas no exercício de cada uma delas.
Mesmo assim, consideramos que a oficina produziu efeitos condizentes com seu objetivo, avançando alguns passos na direção de uma "boa" escolha profissional, tal como definimos no início deste artigo. Com este relato, esperamos ter contribuído para o debate sobre OP, mostrando algumas possibilidades de intervenção com grupo no contexto de uma escola pública.

\section{Luiz Gustavo Silva Souza*}

Psicólogo, Mestre em Psicologia, Doutorando do Programa de Pós-Graduação em Psicologia da Universidade Federal do Espírito Santo (PPGP-UFES).

\section{Maria Cristina Smith Menandro}

Psicóloga, Doutora em Psicologia, professora do Programa de Pós-Graduação em Psicologia da Universidade Federal do Espírito Santo (PPGP-UFES)

\section{Milena Bertollo}

Psicóloga, mestranda em Psicologia pelo PPGP-UFES

Rafaela Kerckhoff Rolke

Psicóloga, mestranda em Psicologia pelo PPGP-UFES

* Endereço para envio e correspondência:

Universidade Federal do Espírito Santo, Cemuni VI. Programa de Pós-Graduação em Psicologia.

Av. Fernando Ferrari, n. 514, Goiabeiras, Vitória - ES - Brasil, CEP: 29075-910

E-mail: luizsouza@hotmail.com.

Recebido 13/05/2008 Reformulado 18/11/2008 Aprovado 26/11/2008

Referências
Abade, F. L. (2005). Orientação profissional no Brasil: uma revisão histórica da produção científica. Revista Brasileira de Orientação Profissional, 6(1), 15-24.

Aguiar, W. M. J., \& Ozella, S. (2003). O sentido subjetivo atribuído à escolha profissional: um estudo com jovens de camadas populares. In S. Ozella (Org.), Adolescências construídas: a visão da psicologia sócio-histórica (pp. 253-276). São Paulo: Cortez.

Bastos, J. C. (2005). Efetivação de escolhas profissionais de jovens oriundos do ensino público: um olhar sobre suas trajetórias. Revista Brasileira de Orientação Profissional, 6(2), 31-43.

Bock, A. M. B., \& Aguiar, W. M. J. (1995). Por uma prática promotora de saúde em orientação vocacional. In A. M. B. Bock (Org.), A escolha profissional em questão (pp. 9-24). São Paulo: Casa do Psicólogo.

Bock, A. M. B., \& Liebesny, B. (2003). Quem eu quero ser quando crescer: um estudo sobre o projeto de vida de jovens em São Paulo. In S. Ozella (Org.), Adolescências construídas: a visão da psicologia sócio-histórica (pp. 203-222). São Paulo: Cortez.

Bock, S. D. (1995). Concepções de indivíduo e sociedade e as teorias em orientação profissional. In A. M. B. Bock (Org.), A escolha profissional em questão (pp. 61-70). São Paulo: Casa do Psicólogo.

Bock, S. D. (2002). Orientação profissional: a abordagem sócio- histórica (2a ed.). São Paulo: Cortez.

Enguita, M. F. (1989). A face oculta da escola: educação e trabalho no capitalismo. Porto Alegre: Artes Médicas.

Matos, K. L. (2003). Juventude, professores e escola. ljuí, RS: Editora da Unijuí.

Oliveira, D. C., Sá, C. P., Fischer, F. M., Martins, I. S., \& Teixeira, L. R. (2001). Futuro e liberdade: o trabalho e a instituição escolar nas representações sociais de adolescentes. Estudos de Psicologia (Natal), 6(2), 245-258.

Patto, M. H. S. (2000). A produção do fracasso escolar. Histórias de submissão e rebeldia. São Paulo: Casa do Psicólogo.

Sarriera, J. C. (2000). Intervenção psicossocial e algumas questões éticas e técnicas. In J. C. Sarriera (Ed.), Psicologia comunitária. Estudos atuais (pp. 25-44). Porto Alegre: Sulina.

Sparta, M., \& Gomes, W. B. (2005). Importância atribuída ao ingresso na educação superior por alunos do ensino médio. Revista Brasileira de Orientação Profissional, 6(2), 45-53.

Zanella, A. V. (2003). Psicólogo na escola e as "dificuldades de aprendizagem": algumas estratégias e muitas histórias. In C. Maraschin, L. B. L. Freitas, \& D. C. Carvalho (Orgs.), Psicologia e educação. Multiversos sentidos, olhares e experiências (pp. 19-32). Porto Alegre: UFRGS. 